\title{
Congenital diaphragmatic hernia: a retrospective study regarding the clinical experience of Bihor County Genetics Center
}

\author{
COSMIN MIHAI VESA ${ }^{1}$, EMILIA SEVERIN ${ }^{2}$, MARIUS BEMBEA ${ }^{3}$, AMORIN REMUS POPA ${ }^{3}$, ALINA \\ SKLERNIACOF $^{4}$, CLAUDIA JURCA ${ }^{1 *}$, KINGA KOZMA ${ }^{1}$, CRISTIAN DAINA ${ }^{6}$, ALEXANDRU JURCA ${ }^{1}$, \\ CODRUȚA PETCHESI ${ }^{1}$, DORINA GALUSCA ${ }^{4}$, SÂNZIANA JURCA ${ }^{5}$, DANA CARMEN ZAHA ${ }^{1}$
}

\author{
${ }^{1}$ Preclinical Department of Preclinical Disciplines, Faculty of Medicine and Pharmacy, University of Oradea, Romania \\ ${ }^{2}$ Genetics Department, "Carol Davila" University of Medicine and Pharmacy Bucharest, Romania \\ ${ }^{3}$ Doctoral school of Biomedical Sciences, University of Oradea, Faculty of Medicine and Pharmacy of Oradea, Romania \\ ${ }^{4}$ Municipal Hospital "Dr. Gavril Curteanu”, Oradea, Romania \\ ${ }^{5}$ Faculty of Medicine and Pharmacy, University of Oradea, Romania \\ ${ }^{6}$ Surgical Department, Faculty of Medicine and Pharmacy of Oradea, University of Oradea, Romania
}

\begin{abstract}
Congenital diaphragmatic hernia is an abnormality of embryologic development characterized by the persistence of communication between the thoracic and abdominal cavities, followed by an extremely high death rate despite medical progress. In Bihor county, according to a retrospective analysis of patient records from the Regional Center of Genetics, 30 children were diagnosed with congenital diaphragmatic hernia over a span of 28 years, from 1990 to 2018 , most being male (73.3\%).

Predominant were the complex congenital diaphragmatic cases, meaning the cases of diaphragmatic hernia associated with other congenital abnormalities, 67\% (20 patients) presenting at least one other congenital malformation. 95\% (19 cases) of patients with complex congenital diaphragmatic hernia presented pulmonary abnormalities, the most frequent being pulmonary hypoplasia; 35\% (7 cases) presented cardiac abnormalities. The Apgar score at 5 minutes after birth was significantly lower for patients with the clinical form of complex congenital diaphragmatic hernia. The mortality for the patients presenting the complex form was $100 \%$, and for the patients presenting the isolated form was $20 \%$. Karyotype analysis was performed for 17 patients, and $23.53 \%$ of them (4 patients) presented chromosomal abnormalities.
\end{abstract}

Keywords Birth defect, congenital diaphragmatic hernia, genetic syndromes.

To cite this article: VESA CM, SEVERIN E, BEMBEA M, POPA AR, SKLERNIACOF A, JURCA C, KOZMA K, DAINA C, JURCA A, PETCHESI C, GALUSCA D, JURCA S, ZAHA DC. Congenital diaphragmatic hernia: a retrospective study regarding the clinical experience of Bihor County Genetics Center. Rom Biotechnol Lett. 2021; 26(3): 2671-2678. DOI: 10.25083/rb1/26.3/2671-2678 


\section{Introduction}

Based on current literature, congenital diaphragmatic hernia $(\mathrm{CDH})$ is a defect in the diaphragm ranging from a thinned area in the diaphragm to its complete absence. Complete absence of the diaphragm is known to be one of the most severe congenital malformations resulting in life-threatening breathing difficulties that are apparent from birth. The defect causes high morbidity and mortality among infant population. Although improvements in medical and surgical management have improved the outlook, survival remains at $60-70 \%$ (SEETHARAMAIAH et al, 2009; WRIGHT et al, 2011). Based on the available literature the incidence of $\mathrm{CDH}$ ranges from approximately $0.8-5 / 10,000$ births and varies across the study population (CHANDRASEKHARAN et al, 2017). In approximately $60 \%$ of cases, $\mathrm{CDH}$ is isolated, occurring in the absence of additional congenital malformations. As many as $40 \%$ of $\mathrm{CDH}$ cases have additional malformations as part of chromosome aneuploidy, monogenic syndromes, or more commonly, a constellation of major and/or minor anomalies that do not form a currently recognizable pattern or have an identifiable genetic basis (POBER, 2008).

In approximately $80-85 \%$ of cases, congenital diaphragmatic hernia is situated on the left side, in $10-15 \%$ of cases on the right side, and in 5\% of cases is bilateral. The largest proportion of diaphragmatic defects involve lateral or posterior components of the diaphragm, such as posterolateral hernia or Bochdalek hernia, and are often associated with the herniation of the stomach, intestines, liver or spleen into the thoracic cavity (STARKER et al, 2012).

Newborns with typical congenital diaphragmatic hernia present respiratory distress, the respiratory symptoms being polymorphic and depending on the degree of hypoplasia and reactive pulmonary hypertension. The clinical presentation varies from immediate respiratory distress with a low Apgar score, to an initial, stable period followed by the onset of respiratory difficulties within 24-48 hours after birth, or even in some cases, to late onset of clinical symptoms, after months or years (WYNN et al, 2014; GRAHAM et al, 2005).

Methods of diagnostic imaging include simple thoracoabdominal X-ray, abdominal and thoracic echography and echocardiography. The simple thoracoabdominal $\mathrm{X}$-ray, the imaging technique of choice for the postnatal diagnosis, reveals one or more of the characteristic radiologic signs. These are as follows: the presence of intestines in the thoracic cavity and contralateral shift of the mediastinum, the ipsilateral lung visible only in the center of the hilum, the rest of the hemi thorax being occupied by a nonhomogeneous opacity with or without transparent areas; other radiological signs could be the presence in the thorax of the stomach/gastric fundus, hydroaeric levels in the thorax, or the intrathoracic herniation of the liver and the absence of intestinal pneumatization (KEIJZER et al, 2010).
Approximatively 10 years ago, congenital diaphragmatic hernia was seen as an immediate urgency which necessitated timely surgical intervention, the surgical procedure being performed right after birth. Following technical progress of newborn reanimation, ECMO was introduced (respiration that uses an extracorporeal membrane). It is a new technique that has improved the survival rate, but it is very costly.

The existence of genetic syndromes associated with congenital diaphragmatic hernia represents some of the strongest evidence that genetic factors play a part in the development of this disease (JONES, 2006) and the methods for diagnosis were improved now (COSIER et al, 2017).

Numerical chromosome abnormalities have been found in approximatively $10 \%$ of cases of congenital diaphragmatic hernia (JURCA et al, 2018). Congenital diaphragmatic hernia occurs in common chromosomal abnormalities such as trisomy $18(10 \%)$, trisomy $13(6 \%)$, and in triploidies. congenital diaphragmatic hernia has also been found in the Turner syndrome. The frequency of chromosomal abnormalities is $18 \%, 2 \%$ if the diaphragmatic hernia is isolated and $34 \%$ if there exist any associated anomalies. There are more than 70 syndromes in which diaphragmatic hernia has been noticed (JURCA et al, 2017). Abnormalities of almost all chromosomes have been found in patients with congenital diaphragmatic hernia, which significantly complicates the discovery of the etiology (BOLLMANN et al, 1995). It appears that mutations of the BCL-2 gene could lead to exaggerated apoptosis of mesenchymal cells (BIELINSKA et al, 2007; ZAHA et al, 2012). The most frequently occurring genetic syndromes associated with congenital diaphragmatic hernia are shown in the Table 1.

Congenital diaphragmatic hernia is an abnormality of significant importance due to the serious consequences on the newborn health. Although not much data existed on the disease's etiology a few years ago, following the progress in the field of genetics, it has become increasingly clear that as far as this congenital anomaly is concerned, the genetic component is significant. Presently, numerical and structural chromosome abnormalities, as well as mutations, are known to be associated with this illness. The study of congenital diaphragmatic hernia offers the possibility of understanding the complexity of this disease and obtaining new information on the role of genes, transcription factors and signaling pathways in diaphragmatic, cardiac and pulmonary embryogenesis.

This study aims to:

- Find out prevalence of diaphragmatic hernia over the last 28 years;

- Describe the clinical particularities of congenital diaphragmatic hernia;

- Describe other congenital malformations associated with diaphragmatic defects;

- Investigate the effect that congenital diaphragmatic hernia has on survival;

- Analyze the disease's risk of reccurrence;

- Detect the possible genetic causes involved in newborns' congenital diaphragmatic hernia. 
Table 1. Monogenic syndromes with congenital diaphragmatic hernia as a clinical manifestation

\begin{tabular}{|c|c|}
\hline Syndrome & Gene \\
\hline Cornelia de Lange & NIPBL \\
\hline Craniofrontonasal & EFNB1 \\
\hline Donnai-Barrow & LPR2 \\
\hline Fryns & Unknown \\
\hline Matthew-Wood & GPRA6 \\
\hline Golabi - Behmel & WT1 \\
\hline Denys-Drash & WT1 \\
\hline Frasier & WT1 \\
\hline Meacham & WT1 \\
\hline WAGR & FGFR2 \\
\hline Apert & CDKN1C, H18, LIT1, NSD 1 \\
\hline Beckwith-Wiedemann & CHD7 SEMA3E \\
\hline CHARGE & CD96 \\
\hline Trigonocephaly & Unknown \\
\hline Coffin-Siris & Unknown \\
\hline Czeizel-Losonci & Unknown \\
\hline Gershoni-Baruch & POCR N \\
\hline Goltz & \\
\hline
\end{tabular}

\section{Materials and Methods}

This paper is a retrospective statistical study regarding congenital diaphragmatic hernia cases which have been diagnosed in Bihor County from 1990 to 2018. The medical records from patients with congenital anomalies were used accessing the archives of the Regional Centre of Medical Genetics Bihor which is part of the Municipal Hospital "Dr. Gavril Curteanu"; these patient records were selected from cases of congenital anomalies, registered over a period of 28 years. Patients' clinical and paraclinical records were included in the study data. Personal data of the newborns regarding date of birth, sex, rank, weight at birth, gestational age, place of provenance, the patient's family history (affected family members), clinical data such as, the type of diaphragmatic defect, its location, associated malformations, the age at onset of disease, the Apgar score, pathological examination and karyotype were used to give an overview of the $\mathrm{CDH}$ in Bihor county.

The study was approved by the Ethics Commission of Medicine and Pharmacy Faculty, University of Oradea and conducted respecting the Declaration of Ethical Helsinki Medical Research Involving Human Principles for Subjects.

\section{Results and Discussion}

Out of a total of 4575 patients with congenital anomalies that were registered in the Regional Center of Genetics Bihor, 30 of the cases present congenital diaphragmatic hernia. The percentage of cases with congenital diaphragmatic hernia out of the total number of congenital abnormalities is $0.65 \%$ (Figure 1).

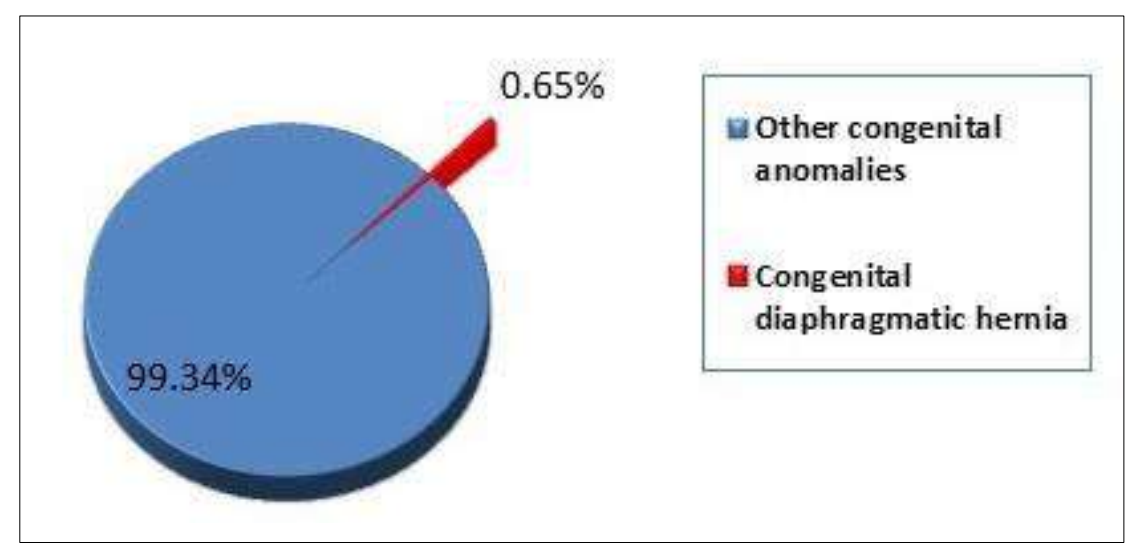

Figure 1. Proportion of congenital diaphragmatic hernia cases reported to the total number of congenital anomalies. 
Out of a total of 30 patients included in the study, $22(73.3 \%)$ patients were male, and $8(26.6 \%)$ patients were female. We note that the male sex is predominant; this is consistent with the data present in the scientific literature (POBER, 2008).

The distribution according to rank is as follows: $7(23 \%)$ children were of rank I, $16(53 \%)$ children were of rank II, $2(17 \%)$ children were of rank III and $2(7 \%)$ children were of higher rank. We note that congenital diaphragmatic hernia occurred more frequently among children of rank II.

Out of the newborns included in the study, $5(16.66 \%)$ were underweight at birth, 22 (73.33) were of normal weight, and $3(10 \%)$ were overweight. The fact that intrauterine fetal growth is not affected by the disease in most cases is due to the maternal-fetal circulation, which fulfills all nutritional needs and oxygenation of the fetus during pregnancy; the fetus does not depend on its own respiratory system, nor on its digestive system, which are both affected by congenital diaphragmatic hernia. As previously stated, the severe consequences of the disease manifest themselves a few minutes after birth, after the first spontaneous breaths, thus congenital diaphragmatic hernia does not influence in utero development with the exception, probably, of the cases with associated cardiac abnormalities.

Out of a total of 30 cases, 2 newborns $(6.67 \%)$ with congenital diaphragmatic hernia had a family history of congenital diaphragmatic hernia.
Of all newborns included in the study, $6(10.00 \%)$ were premature, and $24(80.00 \%)$ were born on term. This fact has favorable consequences, as a significant number of newborns with congenital diaphragmatic hernia need to undergo surgery in the neonatal period, and a welldeveloped fetus represents a positive prognostic factor (GRAHAM et al, 2005; KEIJZER et al, 2010).

As can be observed from the cases that have been analyzed, more frequent were the congenital diaphragmatic hernia cases of newborns who came from an urban environment; 16 children $(53.33 \%)$ came from an urban environment, and 14 (46.67\%) from a rural environment.

Out of a total of 30 patients with $\mathrm{CDH}, 10$ cases (33\%) presented isolated $\mathrm{CDH}$, and 20 cases (67\%) presented $\mathrm{CDH}$ associated with other congenital abnormalities of various types (Figure 2). Compared with the data from the medical literature, which indicates that approximatively $60 \%$ of congenital diaphragmatic hernia cases are isolated and the rest of $40 \%$ are complex (BOLLMANN et al, 1995; POBER, 2008), we observe that among the studied group of patients, complex $\mathrm{CDH}$ was predominant. This can explain the unfavorable prognosis of the newborns included in the study and high perinatal mortality estimated to approximately $70 \%$; multiple abnormalities of organ systems led to such a high mortality rate despite treatment being provided. Similar data were provided by Bielinska et al, 2007.

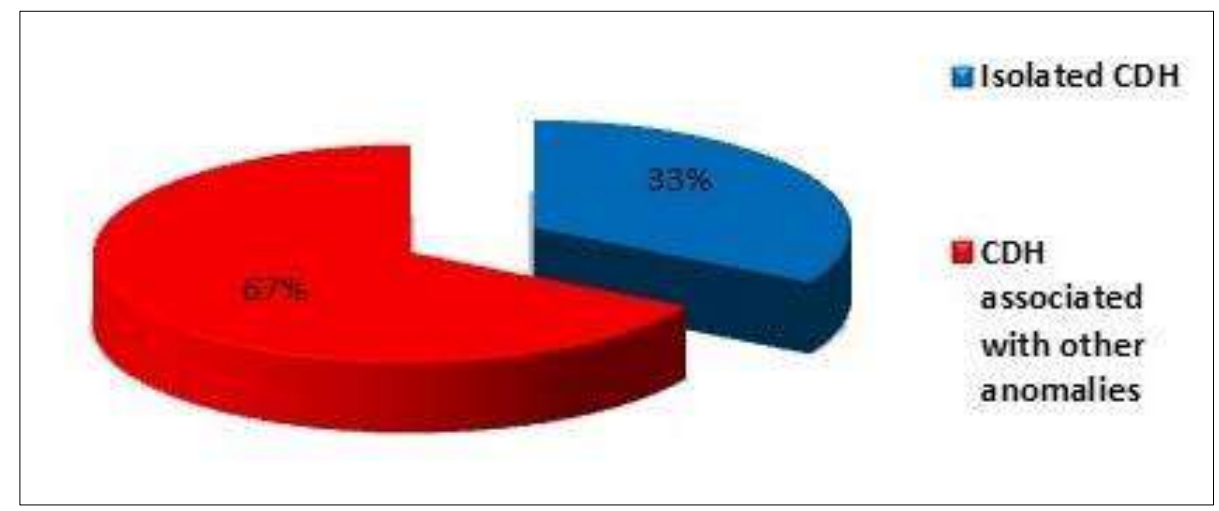

Figure 2. Proportion between isolated and associated congenital diaphragmatic hernia $(\mathrm{CDH})$ cases.

In 26 of cases (96\%), the diaphragmatic defect was situated on the left side, and in only one case (4\%) it was situated on the right, which is consistent with the literature data which specifies that diaphragmatic defects appear in over $80 \%$ of cases on the left side. Among patients with complex congenital diaphragmatic hernia, a vast majority presented pulmonary congenital anomalies - 19 newborns (95\%); the most frequent abnormality was pulmonary hypoplasia. 7 (35\%) patients presented cardiac congenital anomalies, $9(45 \%)$ patients presented digestive anomalies, and $2(10 \%)$ patients presented other types of abnormalities (Figure 3). 


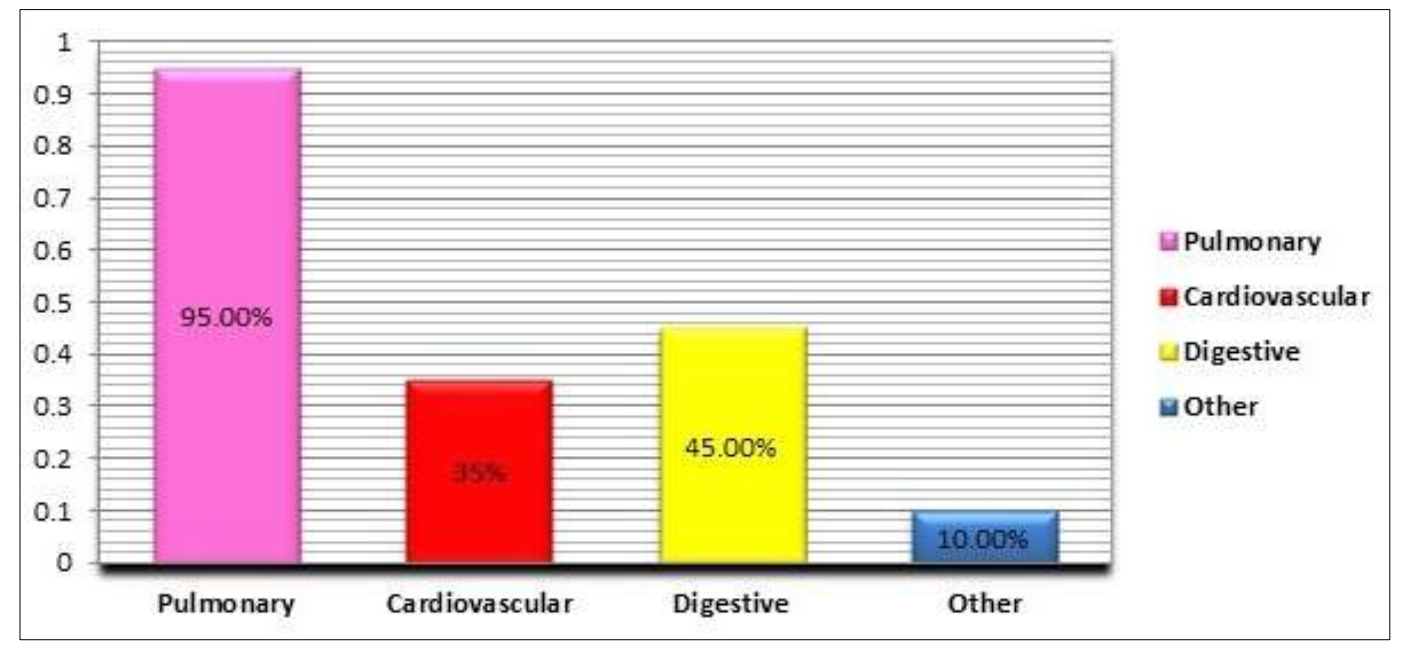

Figure 3. Frequency of associated anomalies among complex congenital diaphragmatic hernia cases.

By analyzing the cases of complex diaphragmatic hernia, different types of congenital malformations were found in each organ system. As far as the respiratory system is concerned, $19(95 \%)$ cases presented pulmonary hypoplasia, and one $(5 \%)$ case presented pulmonary agenesis. At the cardiac level, there was one (5\%) case with patent Botallo foramen, 2 cases $(10 \%)$ with patent arterial duct, $1(5 \%)$ case with transposition of the great vessels, one $(5 \%)$ case of hypoplastic left ventricle, and $2(10 \%)$ patients with dextrocardia. Digestive system malformations included one $(5 \%)$ case of intestinal malrotation, one $(5 \%)$ case presenting common mesentery, and $7(35 \%)$ cases with the stomach and a number of intestine loops present in the thoracic cavity. Other congenital abnormalities included one $(5 \%)$ case of cryptorchidism and one (5\%) case of congenital foot deformity (Table 2).

In most cases $(24,86 \%)$ the onset of the disease occurred in the neonatal period, meaning the newborn's first month of life. An onset past the first month, but before weaning occurred in 2 (7\%) cases, and in another $2(7 \%)$ cases, the onset occurred before the age of 1-year-old, this being considered a late onset. The late onset of the disease, even if found in a small number of cases, highlights the importance of a complete and periodic clinical examination (JURCA et al, 2018). Of course, the age of onset influences the prognosis, since the older a patient is at onset, the better the prognosis. This is due to the fact that a late onset probably involves a smaller diaphragmatic hernia and a more developed child, and thus an increased resistance to surgical stress.

Table 2. Types of associated anomalies according to location

\begin{tabular}{|l|c|c|}
\hline Type of anomaly & No. of cases & Percentage \\
\hline Pulmonary & $\mathbf{1 9}$ & $\mathbf{9 5 \%}$ \\
\hline Pulmonary hypoplasia & 18 & $90 \%$ \\
\hline Pulmonary agenesis & 1 & $5 \%$ \\
\hline Cardiac & $\mathbf{7}$ & $\mathbf{3 5 \%}$ \\
\hline Patent Botallo foramen & 1 & $5 \%$ \\
\hline Patent arterial duct & 2 & $10 \%$ \\
\hline Great vessel transposition & 1 & $5 \%$ \\
\hline Hypoplastic left ventricle & 1 & $5 \%$ \\
\hline Dextrocardia & 2 & $10 \%$ \\
\hline Digestive & $\mathbf{9}$ & $\mathbf{4 5 \%}$ \\
\hline Intestinal malrotation & 1 & $5 \%$ \\
\hline Common mesentery & 1 & $5 \%$ \\
\hline Presence of stomach and intestine loops in thoracic cavity & 7 & $35 \%$ \\
\hline Other congenital anomalies & $\mathbf{2}$ & $\mathbf{1 0 \%}$ \\
\hline Cryptorchidism & 1 & $5 \%$ \\
\hline Congenital foot deformities & 1 & $5 \%$ \\
\hline
\end{tabular}


By comparing the Apgar scores of those patients with associated congenital abnormalities with those patients without, it can be observed that the newborns with isolated congenital diaphragmatic hernia presented higher Apgar scores at 5 minutes after birth, those with complex diaphragmatic hernia having far smaller Apgar scores due to the respiratory, cardiac and digestive abnormalities. The medical literature underlines the importance of the Apgar score at 5 minutes in assessing the prognosis of cases with this pathology (Figure 4).

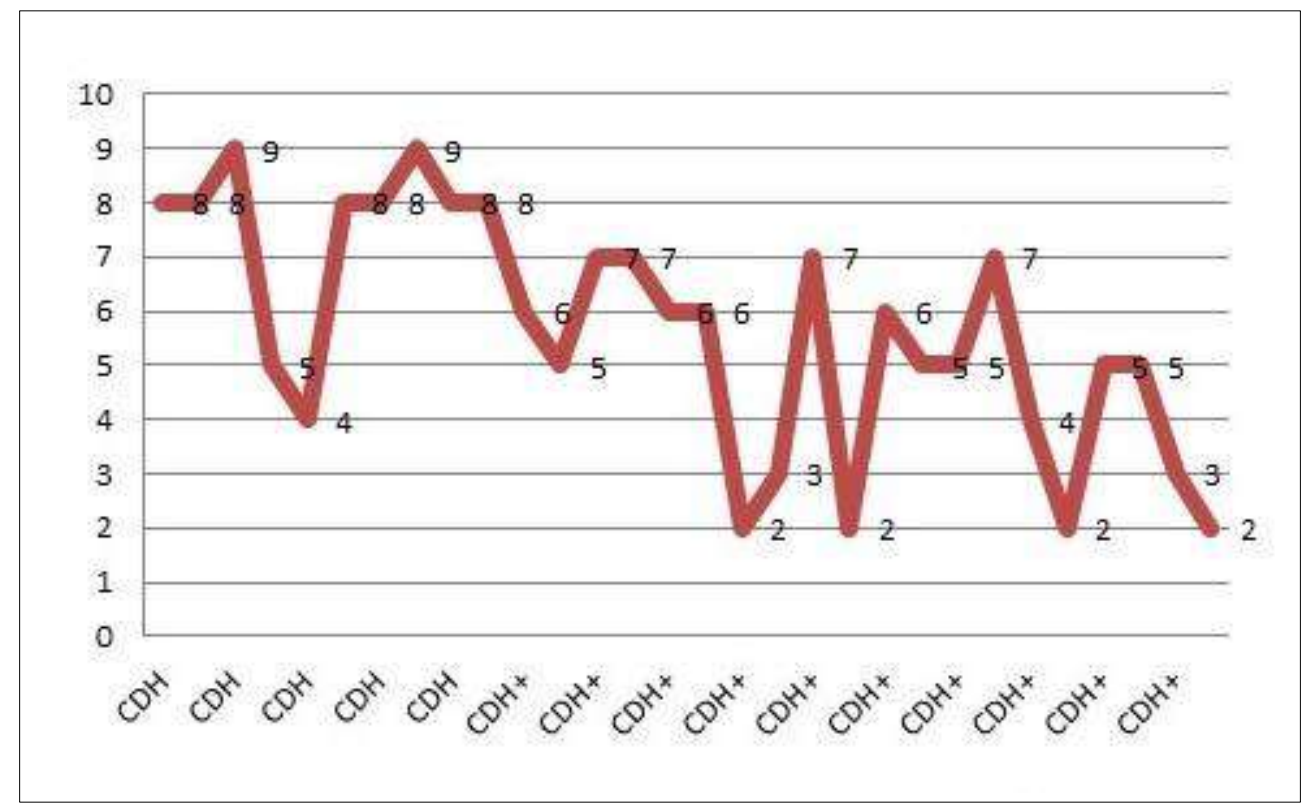

Figure 4. Apgar score at 5 minutes in isolated cases $(\mathrm{CDH})$ and associated cases $(\mathrm{CDH}+)$.

The survival rate of the newborns with this disease was low. A total of $20(66.67 \%)$ patients died within the first month of life, and $2(6.67 \%)$ patients died before being weaned. Of those patients diagnosed with congenital diaphragmatic hernia, only 8 (26.67\%) were long-term survivors. They were the patients that presented isolated congenital diaphragmatic hernia, lacking any associated congenital abnormalities.

Genetic testing was performed in 17 out of a total of the 30 cases analyzed in the study. The genetic testing consisted of performing a karyotype test to identify structural and numerical chromosome abnormalities. Out of 17 cases, 4 of them $(23.53 \%)$ presented genetic abnormalities and $13(76.47 \%)$ did not (CUCU, 2001). These numbers refer only to the structural and numerical chromosome abnormalities. Thus, for the cases where no chromosome abnormalities were found, it is possible that there existed monogenic anomalies that require more advanced techniques such as PCR or DNA sequencing to be detected. The percentage of congenital diaphragmatic hernia cases presenting chromosome abnormalities is consistent with the data from the medical literature, Kosinski et al, 2017 state that in 10-30\% of the cases may be an association with chromosomal defects.

The chromosomal abnormalities that were detected included trisomy $18(50 \%)$, trisomy $13(25 \%)$ and tetrasomy $12(25 \%)$. The cases where chromosomal anomalies could be identified were cases of congenital diaphragmatic hernia associated with additional congenital abnormalities (Figure 5). The 2 cases of trisomy 18 presented, aside from congenital diaphragmatic hernia, pulmonary hypoplasia, transposition of the great vessels, and pulmonary hypoplasia, patent arterial duct, intestinal malrotation, respectively. In the case of the newborn with trisomy 13, pulmonary and left ventricle hypoplasia were identified alongside congenital diaphragmatic hernia. In the case of the newborn presenting a $12 p$ isochromosome, pulmonary hypoplasia and a patent Botallo foramen were associated with the congenital diaphragmatic hernia (SKARI et al, 2000). 


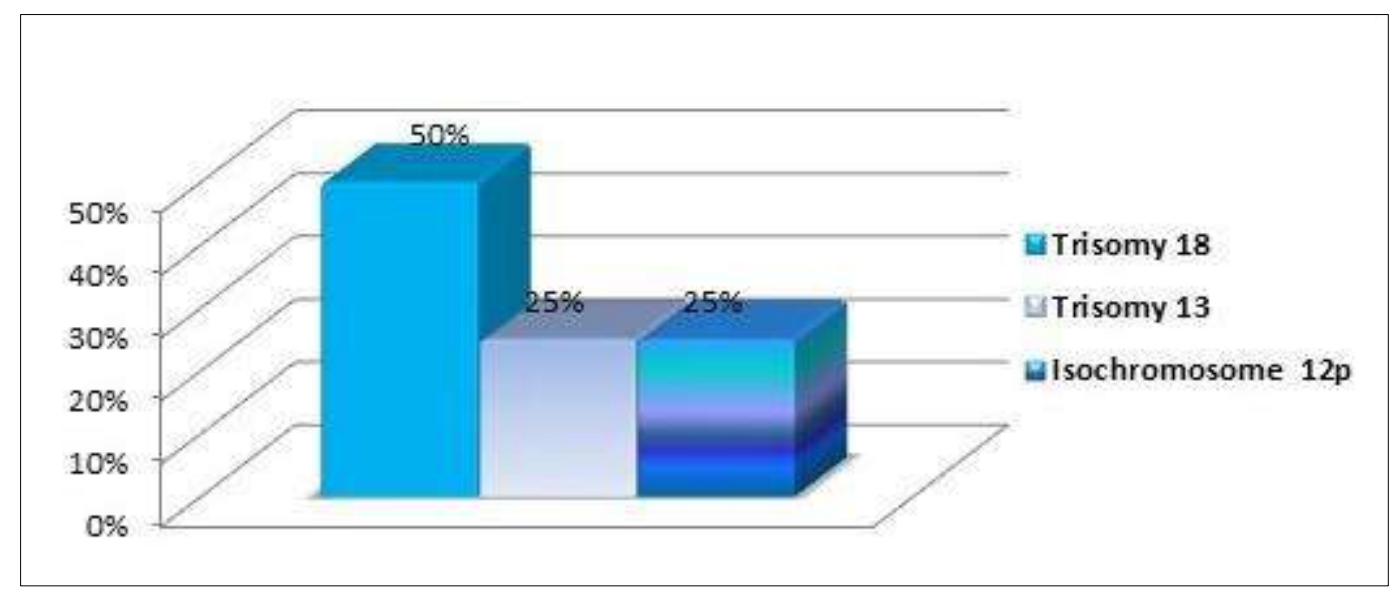

Figure 5. Frequency of chromosomal anomalies among cases with abnormal karyotype.

\section{Conclusions}

Diaphragmatic hernia in Bihor County in time period 1990-2018 occurred more frequently among male newborns. The diaphragmatic defect was situated on the left side in $96 \%$ of cases. $\mathrm{CDH}$ was frequently associated with a wide variety of pulmonary, cardiac and digestive congenital abnormalities, as well as abnormalities of other systems. Within this study, predominant were the cases presenting complex congenital diaphragmatic hernia. Compared with the cases of isolated congenital diaphragmatic hernia, the prognosis of cases presenting complex congenital diaphragmatic hernia was unfavorable. The cases presenting complex congenital diaphragmatic hernia had a markedly worse prognosis than the cases presenting isolated congenital diaphragmatic hernia. The survival rate was low; the majority of newborns with diaphragmatic hernia died in the early neonatal period. In $6.67 \%$ of cases, there was family history of congenital diaphragmatic hernia. Numerical chromosomal abnormalities were identified in $23 \%$ of cases of newborns with complex diaphragmatic hernia.

This study provides data that could help the health care providers to improve their knowledge and clinical practice in $\mathrm{CDH}$.

Author's contributions: All authors have equal contributions to this paper.

\section{Conflict of Interest}

The authors have no conflict of interest to declare.

\section{References}

1. BIELINSKA M, JAY PY, ERLICH JM, MANNISTO S, URBAN Z, HEIKINHEIMO M, WILSON DB. Molecular genetics of congenital diaphragmatic defects. Annals of Medicine, 2007, 39(4):261-274.

2. BOLLMANN R, KALACHE K, MAU H, CHAOUI R, TENNSTEDT C. Associated malformations and chromosomal defects in congenital diaphragmatic hernia. Fetal Diagn Ther, 1995, 10(1): 52-9.

3. CHANDRASEKHARAN PK, RAWAT M, MADAPPA R, ROTHSTEIN DH, LAKSHMINRUSIMHA S. Congenital Diaphragmatic hernia a review. Matern Health Neonatol Perinatol, 2017, 3:6. doi: 10.1186/s40748-017-0045-1

4. COȘIER V, MARIAN M. The advent of genomics and its potential contribution to the development of quantitative genetics, Romanian Biotechnological Letters, 2017, Vol. 22, No. 5, pp.12847-12859.

5. CUCU N. Epigenomics: Unifying Genomics and Proteomics for an Efficient Functional Genomic Approach of the Current Genetic Analysis, Romanian Biotechnological Letters, 2001, Vol. 6, No. 6, pp. 453-468.

6. GENETICS HOME REFERENCE. https://ghr.nlm. nih.gov/condition/congenital-diaphragmatic-hernia\# statistics, Data last accessed: September 19, 2019.

7. GRAHAM G, DEVINE PC. Antenatal diagnosis of congenital diaphragmatic hernia, Semin. Perinatol, 2005, 29(2): 69-76.

8. JURCA AD, KOZMA K, STREAȚA I, PETCHEŞI CD, BEMBEA M, JURCA MC, CUC EA, VESA 
C.M., BUHAŞ CL. Morphological and genetic abnormalities in a Jacobsen syndrome. Rom $J$ Morphol Embryol, 2017, 58(4): 1531-1534.

9. JURCA C, BEMBEA M, PALLAG A, MUREŞAN M, SZILAGYI A, BALMOȘ A, POP O, JURCA A, DOBJANSCHI L. Pharmacotherapeutical considerations in the treatment and management of neonatal hyperammonaemia. Farmacia, 2018, 66(2): 216-222.

10. JURCA MC, BEMBEA M, IUHAS OA, KOZMA K, PETCHEŞI CD, JURCA AD, SZILÁGYI A, DUBĂU DL, SAVA CN, ZAHA DC, CUC EA. Double autosomal trisomy with mosaicism 47, XY $(+8) / 47, \mathrm{XY}(+21)$. Morphological and genetic changes of a rare case, Rom J Morphol Embryol, 2018, 59(3): 985-988.

11. KEIJZER R, PURI P. Congenital diaphragmatic hernia. Semin. Pediatr. Surg, 2010, 19 (3): 180-185.

12. KOSIŃSKI P, WIELGOŚ M. Congenital diaphragmatic hernia: pathogenesis, prenatal diagnosis and management - literature review. Ginekol Pol., 2017, 88(1): 24-30.

13. POBER BR, Genetic aspects of human congenital diaphragmatic hernia. Clin Genet, 2008, 74(1): 1-15.

14. SEETHARAMAIAH R, YOUNGER JG, BARTLETT RH et al. Factors associated with survival in infants with congenital diaphragmatic hernia requiring extracorporeal membrane oxygenation: a report from the Congenital Diaphragmatic Hernia Study Group. J Pediatr Surg, 2009; 44: 1315-1321.

15. SKARI H, BJORNLAND K, HAUGEN G, EGELAND T, EMBLEM R. Congenital diaphragmatic hernia: a meta-analysis of mortality factors. Journal of Pediatric Surgery, 2000, 35(8): 1187-97.

16. STARKER G, STABOULIDOU I, BECK C, MILLER K, VON KAISENBERG C. Genetics of Congenital Diaphragmatic Hernia. In: E. Molloy, Congenital Diaphragmatic Hernia - Prenatal to Childhood Management and Outcomes, InTech, 2012, pp. 59-92.

17. WRIGHT JC, BUDD JL, FIELD DJ et al. Epidemiology and outcome of congenital diaphragmatic hernia: a 9-year experience. Paediatr Perinat Epidemiol, 2011; 25: 144-149.

18. WYNN J, YU L, CHUNG WK. Genetic causes of congenital diaphragmatic hernia. Semin Fetal Neonatal Med, 2014, 19(6): 324-330.

19. ZAHA DC, LAZAR E. Molecular characterization of apoptosis by the immunohistochemical evaluation of Bcl-2 in breast cancer, Rom J Morphol Embryol, 2012, 53(1): 155-160. 